\title{
Effects of Institutional Consistency on Data Generation and Quality in the Public Sector: A Case of the North West Province of South Africa
}

\author{
Joel Marumo Mosenogi (Mr.) \\ Economist: North West Department of Finance, South Africa \\ Olebogeng David Daw, (Prof.) \\ Senior Lecturer, North West University, Department of Economics
}

\begin{abstract}
Government department restructuring have a huge impact on budget allocation especially when the mandate of such a department changes. Various budget lines are affected, human resource component get affected as well as capital resources to execute departmental mandate also get affect. The longest stable period for the North West departmental names and mandate is four years while other government component has changed more than six times. Evidently, these changes have had a huge impact on data generation, quality, sustainability and publication. Hence it remains a challenge in the North West province to get access to government time series data on different variables, especially finances.
\end{abstract}

Keywords: Data Quality, Data Generation, Consistency, Government

DOI: $10.7176 / \mathrm{IKM} / 9-1-01$

\section{Introduction}

In 1994 South Africa witnessed the new era of democracy which needed new Constitution, political leadership and a complete reform in its administration institutions. Following the election of 27 April 1994, Nelson Mandela was sworn in as President of the Republic South Africa. The Government of National Unity was established; its cabinet made up of twelve African National Congress representatives, six from the National Party, and three from the Inkatha Freedom Party. Thabo Mbeki and F.W. de Klerk were made deputy presidents. Economically, the government embarked on the Reconstruction and Development Programme (RDP) to address the socio-economic consequences of apartheid, including alleviating poverty and addressing the massive shortfalls in social services across the country - something that the government acknowledged would rely upon a stronger macroeconomic environment, (Wikipedia, 2018).

Under the presidency of Nelson Mandela of the new democratic South Africa, in 1994 South African government was divided into 9 provinces as shown in table 1 below with each assigned Premier to oversee its political and administration responsibilities. According to Wikipedia (2018), in 1995, the interim constitution agreed during the negotiations to end apartheid was replaced by a new constitution. A Growth, Employment and Redistribution (GEAR) strategy was adopted in June 1996. The GEAR strategy was influenced by the economic ideas that became known as the Washington Consensus; it aimed to cut state expenditure, rationalise the public sector and reduce the budget deficit to $3 \%$ by 1999 . Trevor Manuel had just been appointed Minister of Finance. The GEAR strategy was probably adopted under some pressure from international investors, (Wikipedia, 2018).

As indicated in table 1, amongst the nine (9) province the North West province was led by the then Premier Popo Simon Molefe from 1994 to 2004. Under his premiership, the province had 14 government departments. These departments were to ensure legislations and policies implementation to attain the desired development of the state. In the process of such implementation, huge amount of data is generated. The primary question in this study is focused on such data generation, weather was and is correctly capture, managed and quality controlled. As argued by Management Study Guide (2018), Government sources provide an extremely rich pool of data for the researchers. In addition, many of these data are available free of cost on internet websites. There are number of government agencies generating data. The stability or change in institutional arrangements may one way or the other affect generation of both qualitative and quantitative data quality and consistency, (Management Study Guide, 2018).

According to OpenDataMonitor (2017), data generation "occurs" in the course of an agency or department fulfilling its public task. Data that accrue are regularly processed in ICT systems, however, rarely with the goal of publishing the raw data. Instead, data are often generated without any regard for the data itself and its further use, but with a strong focus on processing the citizen's concerns. Thus, data generation activities are largely uncoupled from the data's extraction and publication. This has an impact on what data is stored and how it is defined, measured etc., (OpenDataMonitor, (2017).

The responsibility for data management lies primarily with researchers, but institutions and organisations can provide a supporting framework of guidance, tools and infrastructure and support staff can help with many 
facets of data management. Establishing the roles and responsibilities of all parties involved is key to successful data management and sharing, (Van den Eynden, etal, 2011). It is on these bases that this study seeks to establish the effect institutional stability can have on the ability of the generation and quality of data which will enable researchers and academics to provide quality evidence for policy architect, planning and effective and efficient resource allocation.

\section{Literature Review}

The data that public administration accrues in the course of fulfilling its public task is stored in a countless variety when it comes to medium, format, location etc, (OpenDataMonitor, 2017). Even considering only digitized data as potential open data, data storage is still very diverse. From data stored on a local Personal Computer (PC) to large data bases in computing centres, from a variety of proprietary formats used by different Information and Communication Technology (ICT) vendors to some open formats, the diversity appears barely tameable. The particularities of Information Technology (IT) governance in the public sector (Hunnius, Schuppan, et al., 2014) seem to play a role, where Communications and Information Office (CIOs) and ICT strategy units have difficulties to enforce coherent standards, as well as the role and importance of data management in the public sector in general. At least in the German case, public ICT service providers (Hunnius \& Schuppan, 2011) that often run applications, store data and consolidate ICT procurement, have - to a varying degree - overtaken some of the roles here. However, a comprehensive overview of all the data within a jurisdiction does not seem to exist and it remains unclear whether it exists within the numerous administrative silos, (OpenDataMonitor, 2017).

As argued by Jarrar (2017), today, fast-moving and evolving trends in digital technologies are leading to a radical change in citizen expectations. Citizens are changing their approach to interacting with, and relating to, governmental organizations and services. The nature of these evolving interactions is horizontal, empowering and spontaneous. In many ways, the exact opposite of the traditional hierarchical, bureaucratic and rules-based systems government developed over the decades. Central to this new form of interaction is data: up-to-date, reliable, user-friendly and open data. Thus the important role played by government in generating data can never be ignored.

The need for data is no longer a luxury for academic exercise but a need for policy and evidence based decision making. Economies are driven by data. In his article, Haggart (2018) pointed out the following key point for government's role in constructing the data-driven economy:

- The generation, control and use of data are inherently political activities governed by formal and informal laws, regulations and norms.

- Because the rules governing data have society-wide effects, governments have an important role to play in constructing and limiting the market for data.

- In regulating this economy, policy makers must take into consideration the unique dynamics of a databased economy and the central political issues of control over and use of data.

- Governments must also confront the reality that the surveillance required for the efficient functioning of a data-driven economy conflicts with, among other things, the norms supporting a liberal-democratic society.

Data is therefore not required for academic exercise only but in the current digital economy it has a significant bearing on academic, economic, social and political sphere. According to Berlin (2006) high quality data are critical to decision making and gives greater acceptance and confidence in the data we are using for analyses and decisions. Inability of government to manage and store produced data systematically could therefore lead to poor or absence of data for decision-making and effective service delivery due to frequent changing institutional mandate and names.

\section{Methodology and Data Analysis}

Both qualitative and quantitative approaches are used in this study. Data is a major challenge. It took the author 3 weeks to get data. Data found had to be mined first from the South African National Treasury because for three weeks the North West Provincial Treasury could not provide data as per the request of the author. This clearly is an indication of a challenge faced by government on data generation, quality control, management and availability for use by researchers and policy-makers. Names of departments were sourced from South African National Treasury from 1999 to 2018 and name changes and components were coded so that their frequency of movement and changes can be accurately measured. Graphical representation of data trends is therefore used to address objectives of the study

\section{Results}

Government department restructuring have a huge impact on budget allocation especially when the mandate of such a department changes. Various budget lines are affected, human resource component is affected as well as 
capital resources to execute is also affected. Thus lack of consistency in departmental structure and mandate distorts accumulated data and generation thereof. As shown in figure 1 below, the longest period of departmental consistency in the North West province is four (4) years which is for two (2) periods, 1999 to 2002 and 2015 to 2018 Departmental names and mandates have changed nine (9) times in the North West province over the past nineteen (19) years with the exclusion of year 2010 were North West data is not available in the National Treasury database.

Figure 1

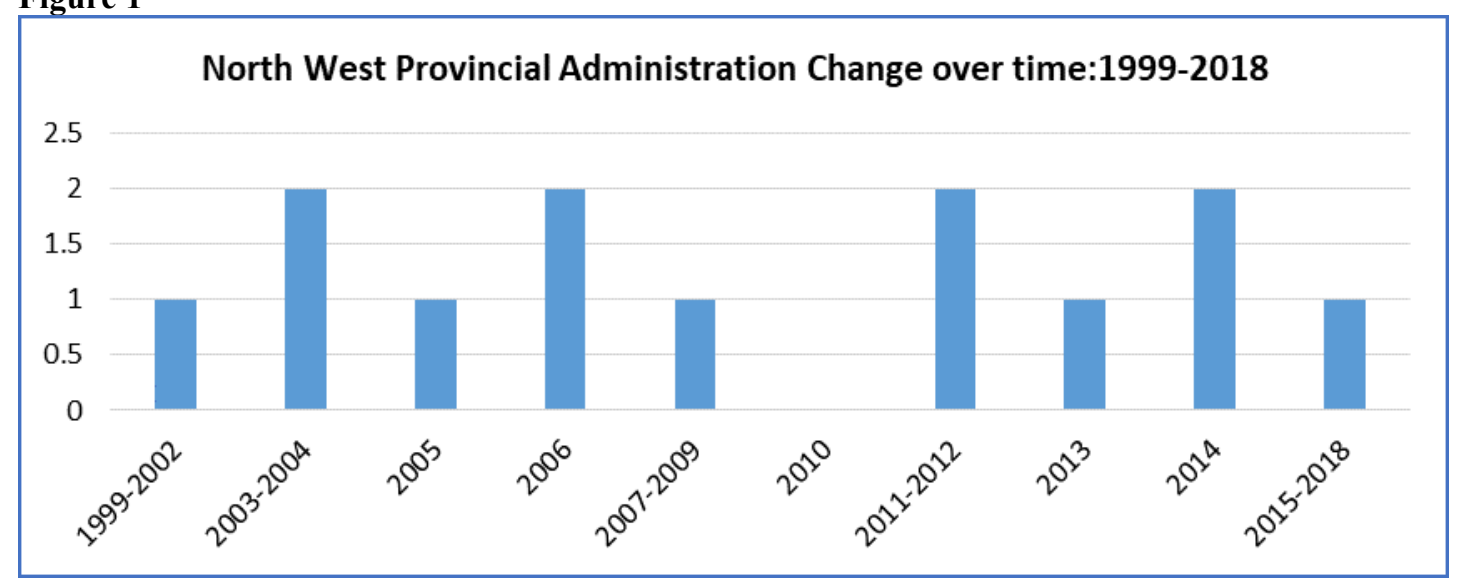

Data Source: South African National Treasury (2018)

Figure two (2) below show a clear picture of the fluctuation of departmental name and mandate changes overtime.

Figure 2

\section{Name and mandate Change: 1999-2018}

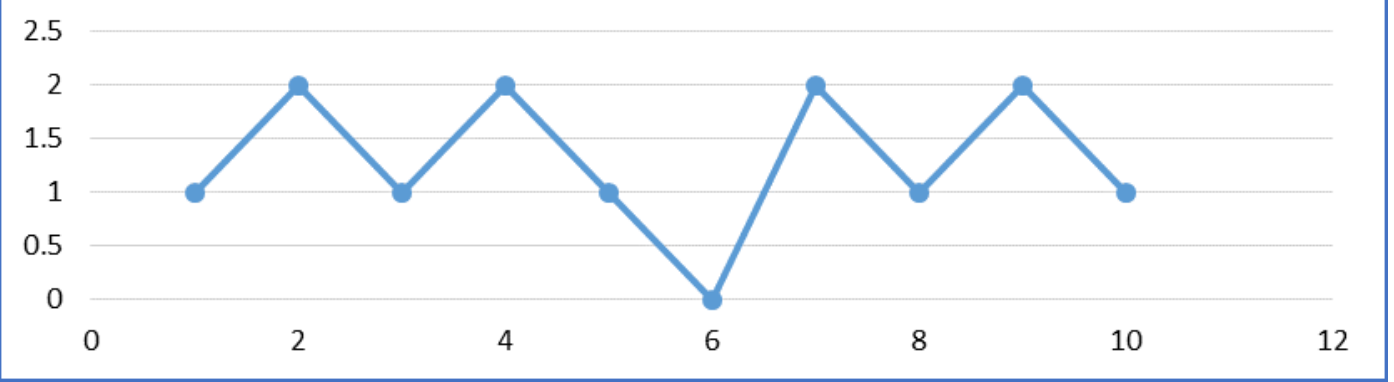

Data Source: South African National Treasury (2018)

Though departments have had changes in name and mandate, there are specific departments which remained unchanged for the past 20 years. These departments include Office of the Premier, The Provincial Legislature and the Department of Health. For further analysis the study disaggregate data into components forming a department at one stage or the other to trace the most volatile component and government mandate. Figure 3 below shows the departmental and component frequency and stability from 1999 to 2018 .

Figure 3

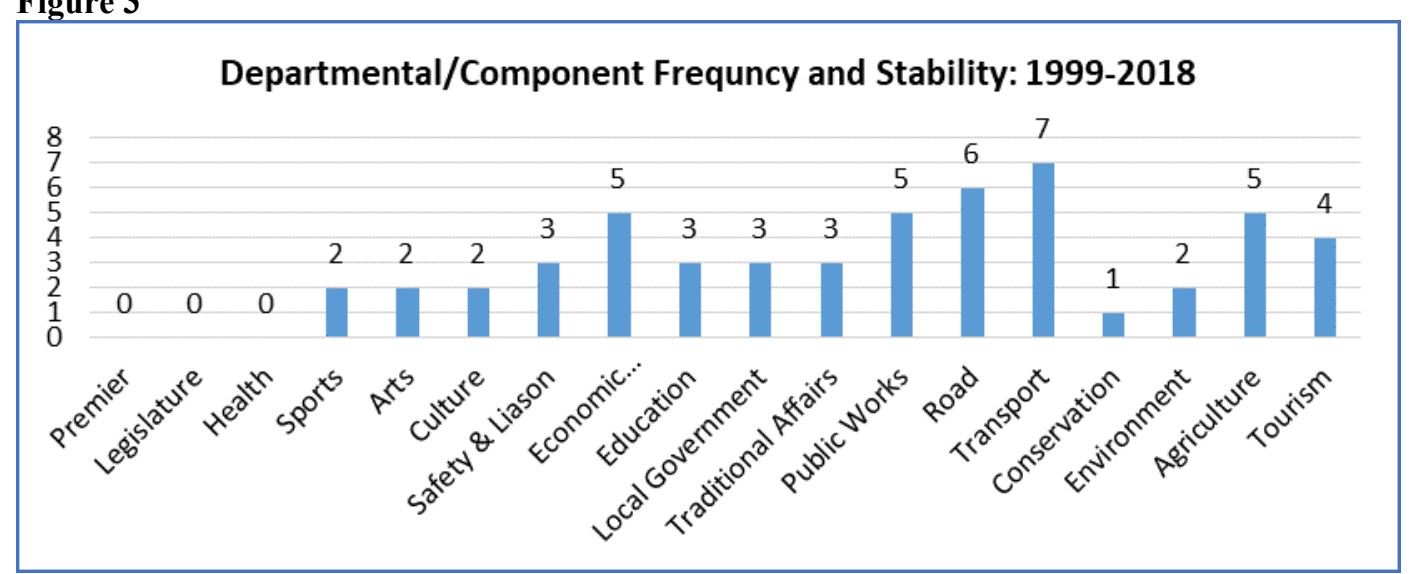

Data Source: South African National Treasury (2018) 
The most frequent of changed government mandate in the past 19 years have been that of Transport which changed seven times followed by Roads changing six times and Agriculture, Public Works and Economic development being there third most volatile components changing 5 times over 19 years. Tourism moved four time and ultimately became a stand-alone department from 2015 to date. The lowest moved component was conservation which moved only once followed by sport; Arts; Cculture and Environment which moved two time and Safety \& Liaison; Education; local Government and Traditional Affairs which all moved and changed three times.

The inability of government in the North West Province to provide policy makers, researcher and planners with a time series from 1994 to 2017 on compensation of employees, infrastructure investment both budgeted for and actual expenditure per department is a practical example of amongst others, the effects of government departments restructuring on data production and quality management thereof amongst others.

Such changes have impacts at various levels that requires time series data for and have impact on:

- Monitoring and evaluating government department's;

- Its impact on both macroeconomics and socio-economic environment and most importantly,

- Long term Planning;

- Evidence based resource allocation;

- Advance performance management;

- Leadership stability and continuity;

- Organizational memory stability and continuity;

- Policy development and implementation such as NDP;

- Quality of Audit information;

- TheeEffective execution of audit findings and action plan thereof

According to Vermont Government Commission (2016), longer terms will also encourage longer term planning as the state identifies needs and develops programs to respond to long term economic development opportunities, infrastructure, and financial and human resource allocation.

It is therefore evident that government restructuring could have a serious impact on data generation and quality not to mention readily available data from research, policy analysis, monitoring and evaluation. This affects budget allocation, which in turn affects the quality of data generation.

\section{Conclusion}

The ability to utilise and analyse data is going to be one of the biggest drivers of business in the future. This enables a better understanding of one's business and customer requirements, (Maxwell, 2018). Forming part of this journey is the shift towards a more mobile-centric landscape that sees people expecting to have access to real-time information for informed decision-making, (Maxwell, 2018). If data remains so critical for service delivery, the big question today could possibly be, what impact does ignorance of data have on increasing service delivery protest or what impact could have recognition and application of made in fast-tracking government services? In the same spirit, inability to generate data simply means we remain decades behind.

Evidently so, change in institutional mandate over time in the North West Province have been one of the reason the government have not been able to produce consistent data for the past 20 years or more. Every time a mandate of the department changes, it affects the budget allocation, human resource and finally data production and were data is produced is of a poor quality.

\section{Reference}

Berlin K. (2006). Framework for Data Governance to improve data quality and understanding of shared assets. Stony Brook University.

Jarrar Y. (2017). What is the role of government in the digital age?. World Economic Forum, Hult International Business School.

Maxwell A. (2018). The Role of Data and Analytics in the Fourth Industrial Revolution. Head of Strategic Consulting at Decision Inc.

MSG (2018). Sources of Data, Experimental Methods. Management Study Guide, Marketing Research.

South African National Treasury (2018). Provincial Budget Informations. South Africa.

Van den Eynden V. etal,. (2011). Managing and Sharing Data, Best Practice for Researchers. UK Data Archive, May 2011.

Vermont Government (2016). Government Restructuring and Operations Review Commission Final Report. 
Table 1: 9 Provinces of South Africa and Premiers in 1994

\begin{tabular}{|l|l|}
\hline Province & Premiers \\
\hline Western Cape & Hernus Kriel \\
\hline Gauteng & Tokyo Sexwale \\
\hline North West & Popo Simon Molefe \\
\hline Eastern Cape & Raymond Mhlaba \\
\hline Free State & Mosiuoa Lekota \\
\hline KZN & Frank Mdlalose \\
\hline Mpumalanga & Methews Phosa \\
\hline Limpopo & Ngoako Ramatlhodi \\
\hline Northern Cape & Manne Dipico \\
\hline
\end{tabular}

Source: Wikipedia (2018) 